\title{
The Evolution of Public Health Education and Training in the United Kingdom
}

\author{
Katie Cole, BSc, MBChB, MscPH, DFPH, ${ }^{1}$ \\ Fiona Sim, MB, BS, MSc, LLM, FFPH, FRCP, ${ }^{1}$ \\ Helen Hogan, MB BS, MSc, FFPH ${ }^{1}$
}

\begin{abstract}
The United Kingdom has a long and evolving history of public health education. From the initiation of formal standardised training for Medical Officers for Health in the early 1900 s, to the current national public health training programme, public health education has adapted to the changing contexts of public health practice. Whilst the profession was originally only a medical specialty, subsequent recognition of the skills and contribution of the wider public health workforce has led to changes in professional specialist training for public health, which is now open to non-medical applicants. This well-established professional training scheme allows the formal accreditation of competence in a broad range of public health skills. The academic component of public health training is provided by a rapidly growing number of postgraduate courses. Once confined to the UK's first school of public health, the London School of Hygiene and Tropical Medicine and a handful of British Universities, the current 60 or so courses across the country are found in diverse university settings. Quality and standards in higher education are monitored by the Quality Assurance Agency for Higher Education but there are no other professional accreditation schemes for postgraduate courses in public health nationally. Public health education and training continues to face challenges in the UK, notably the current government plans for major restructuring of the National Health Service (NHS) which threatens the loss of traditional NHS training placements and has created uncertainty around how professional training might be structured in the future. Whilst the long established tradition of public health education and more recent adoption of competency-based approaches to training gives some flexibility to meet these challenges, insight and innovative responses are required to ensure that public health education and training are not destabilised by these challenges. Revisions of the curricula of postgraduate courses and the competencies required for professional accreditation along with provision of experience in the new locations where public health is to be practiced in the future
\end{abstract}

\footnotetext{
${ }^{1}$ London School of Hygiene and Tropical Medicine, Department of Health Services Research and Policy, University of London.

Corresponding Author Contact Information: Helen Hogan at helen.hogan@1shtm.ac.uk; London School of Hygiene and Tropical Medicine, Department of Health Services Research and Policy, 15-17 Tavistock Place, University of London, London, WC1H 9SH, UK.
} 
will be key to ensuring that public health professionals are ready to tackle the key issues that confront them.

Key Words: Public health education, training, United Kingdom, Master of Public Health, Faculty of Public Health, professional competency.

Recommended Citation: Cole K, Sim F, Hogan H. The Evolution of Public Health Education and Training in the United Kingdom. Public Health Reviews. 2011;33:87104.

\section{INTRODUCTION}

From the pioneering work of Edwin Chadwick on the importance of sanitation in $1843,{ }^{1}$ through to the Black, Acheson and Marmot reports ${ }^{2-4}$ highlighting the impact of socioeconomic inequalities on health, public health professionals in the United Kingdom have done much to raise the profile of issues that have a negative impact on population health. Their influence has persuaded governments to take action on issues such as smoking in public places, potentially improving the health of large numbers of people. ${ }^{3}$ These important contributions have been made against a backdrop of increasingly organised education and training opportunities for those seeking to pursue a professional public health career in academic or National Health Service (NHS) settings.

In the UK, the education and training of specialists in public health has a long and respected history, with a reputation for high standards and internationally recognised qualifications. ${ }^{4,5}$ More recently, the educational and training needs of the public health's diverse workforce have been recognised both through the opening of specialist training schemes to nonmedical applicants and the creation of skills and knowledge frameworks to guide professional development for this wider workforce. At the same time, there has been an expansion of university courses at both postgraduate and undergraduate levels to address the demand for academic qualifications in public health.

This paper describes the evolution of public health education in UK universities and of professional specialist training in public health, with particular focus on England post-devolution. It highlights the changes that have taken place to accommodate an evolving workforce in what was for so long an exclusively medical specialty, and the need to address the challenges generated by frequent changes in public health policy and the structural framework in which public health specialists work. Finally, we consider the current government's proposals for further major changes to the public health system in England, and the likely impact on training and education that this may have. 


\section{THE HISTORY OF EDUCATION AND TRAINING IN PUBLIC HEALTH}

The sanitary reforms of the 19th century led to the organisation of provision of public health in Britain. Following the publication of the Royal Sanitary Commission $^{6}$ in 1871, Local Authorities became responsible for public health and social welfare and Medical Officers of Health (MOsH) were appointed to lead developments in these areas. To meet a recognised need for standardised training, a postgraduate certificate in "State medicine" called the Diploma in Public Health (DPH) was instituted in the same year. ${ }^{5}$ This Diploma, regulated by the medical professions' standard setting body, the General Medical Council (GMC), became the accrediting examination for MOsH. Universities including Edinburgh, Cambridge, Manchester and London were prompted to develop courses to prepare individuals for the exam.

By 1919, all publicly funded preventative activities and health care were unified into a single system at local authority level. Despite the broadening of responsibilities of the MOsH which included oversight of hospitals, personal medical services for the vulnerable and management of specific diseases such as tuberculosis, the curriculum for the DPH remained slow to change focussing largely on epidemiology, population statistics and communicable diseases. ${ }^{6}$ Key United States reports by Flexner ${ }^{7}$ and WelchRose $^{8}$ published at the time and calling for an increase in the scientific content of health professionals' education stimulated universities to review the provision of postgraduate education in Britain. Supported by the Rockefeller Foundation, the London School of Hygiene and Tropical Medicine (LSHTM), the first 'School of Public Health' in the UK, was founded within the University of London in $1924 .{ }^{9}$ With a statutory requirement for all MOsH to possess the $\mathrm{DPH}$, preparing candidates for the Diploma formed the background to much of the School's early work.

Following the establishment of the NHS in 1948, the role of the MOsH shrank as hospital and general practitioner services transferred to the new system. Reforms in 1974 saw all residual personal health services transferred from Local Authorities into health authorities which were also required to employ a board-level medical specialist capable of considering and planning for the health needs of the local population. At that time, the LSHTM played an important role through its Centre for Extension Training in helping to reorient MOsH in preparation for this transfer.

Despite a growing interest in how the social determinants of health and illness interacted with disease since the 1930's and the introduction of departments of Social Medicine in a number of universities, it was not until 
the 1960's that there was recognition of the need to incorporate teaching in the social sciences into public health education. As well as practical training in the workplace, the professional training in public health included an academic component delivered by either modular 'day release' regional consortia programmes or full-time Masters courses. These courses incorporated the new disciplines of sociology and psychology.

In response to a number of high profile system failures related to communicable disease outbreaks and falling recruitment, the Acheson Report (1988) reconsidered the fundamental role of public health specialists within the NHS. ${ }^{10}$ Emphasis was placed on the need for epidemiological skills to enable priority setting, service planning and evaluation of outcomes, the ability to develop and implement health improvement programmes, surveillance of non-communicable diseases, expertise in the coordination of the control of communicable disease and competence in providing independent advice on a range of public health issues to local organisations and the public. These continued to be the basic role requirements for consultants in public health and their teams during the 1990's following the dissolution of health authorities and the formation of Primary Care Trusts (PCTs) with, from 1997, an increasing emphasis on the need to address health inequalities.

\section{Table 1}

Key Dates in the Evolution of Public Health Education and Training

\begin{tabular}{c|l}
\hline 1871 & $\begin{array}{l}\text { Organisation of public health in Britain; appointment of Medical Officers of } \\
\text { Health and introduction of the Diploma in Public Health. } \\
\text { Founding of the first school of public health, the London School of Hygiene and } \\
\text { Tropical Medicine. } \\
\text { The emergence of university Masters courses in public health. } \\
\mathbf{1 9 7 2}\end{array}$ \\
$\begin{array}{l}\text { The UK Faculty of Community Medicine created and standardisation of } \\
\text { professional training in public health. } \\
\text { Professional training in public health open to non-medical applicants. } \\
\text { Development of competency-based curriculum for professional training. }\end{array}$ \\
\hline
\end{tabular}

\section{ACADEMIC PUBLIC HEALTH}

Postgraduate courses in public health in the UK are no longer orientated around the academic needs of those undertaking professional training in the discipline. The curricula of these degrees has expanded to accommodate 
the range of knowledge and skills required by those working in public health in the 21 st century but continue to feature the traditional subjects of epidemiology and statistics, behavioural sciences and health promotion, communicable disease control, environmental health and health economics, often as 'core' or compulsory components. Modular organisation allows flexibility to introduce subject areas such as leadership, management and public health ethics and to respond to a rapidly changing world by adding teaching on emerging public health topics including globalisation and conflict.

With the growth of the multidisciplinary public health workforce and the subject increasingly attracting interest from a wider audience, there has been greater demand for academic courses. Postgraduate education in public health is regarded as an excellent preparation for anyone intending to develop a career in public health. In the UK, it is customary for graduates of such courses to then apply for posts in public health to gain relevant practical experience. However, robust information on graduates' career destinations is lacking.

There are two major sources of public health careers information available to the increasing numbers of students studying public health at Bachelors or Masters levels. The Faculty of Public Health (FPH) publishes information outlining the role of a professional specialist in public health, conditions for entry to specialist training and the nature of that training. The Public Health Online Resource for Careers, Skills and Training $(\mathrm{PHORCaST})^{11}$ provides information aimed at a wider audience than the FPH provision, offering advice on education, training and career planning. It has information on the variety of job options available in public health, how to start a career in the field and what competencies are required. The site also provides access to a range of resources including a report mapping professional public health competencies onto course content for a number of Masters level degrees. Currently around 30 universities in the UK offer a postgraduate qualification in public health. ${ }^{12}$ A further 36 offer Masters on particular aspects of public health such as nutrition, policy, the environment, research, management, nursing or communicable disease prevention. ${ }^{10}$ The structure of programmes is diverse with varying emphasis on research, taught components or learning in practical settings. However the majority are yet to align themselves with the European norm and remain year long courses. ${ }^{13}$ In addition, most have relatively short practical placements or opportunities for independent research of usually three months or less. In the last decade there has been growth in undergraduate (Bachelor) degree courses. Currently, the universities' central application 
service (UCAS) includes more than one hundred degrees that have a public health component. ${ }^{14}$

Following current trends in UK higher education all these courses attract significant numbers of students from overseas. This has led to the need to introduce specific language requirements for entry, along with ongoing support in academic writing skills and group work skills. It has also become important at the start of programmes to describe the UK health context so that case studies arising from the UK NHS can be understood and to use a wider range of case studies from both developed and developing countries.

With burgeoning numbers of university courses covering elements of public health, interest has grown in whether course accreditation can help guide students toward the courses most suitable to their individual needs. In 2010, the FPH decided against accrediting postgraduate courses judged to provide suitable academic preparation for their own professional examinations on the grounds of excessive administration costs and because trainees already received informal advice from their training programme directors. More recently, the Association of Schools of Public Health in the European Region (ASPHER) announced plans to operationalise a European accreditation programme for public health courses in universities across the region from 2011. The level of uptake in the UK, which already has two competency-based frameworks for public health professional development, designed by FPH ${ }^{15}$ and the Skills for Health - Public Health Skills and Careers Framework, ${ }^{16}$ respectively, looks uncertain. Some universities wishing to attract more international students may feel that acquiring an externally recognised quality mark is to their advantage. Any future changes in course structure as a result of the Bologna Process to create a European Higher Education Area based on international cooperation and academic exchange ${ }^{17}$ could make UK courses potentially more attractive to European applicants which, in turn, may influence uptake up of European accreditation.

\section{THE DEVELOPMENT OF PROFESSIONAL TRAINING IN PUBLIC HEALTH}

The UK Faculty of Community Medicine (subsequently renamed the Faculty of Public Health Medicine and later still the Faculty of Public Health) was established under the wing of the three UK Royal Colleges of Physicians in 1972 to provide a professional home to the specialist public health physician workforce. ${ }^{4}$ After the major reorganisation of the public health service in England, Scotland and Wales in 1974, standards of education and training for public health physicians were expected to be 
equivalent to those for other medical specialties. The FPH developed a national training curriculum which has been revised on a number of occasions, most recently in $2010 .{ }^{18}$ In the 2010 revision the skills and attitudes needed to deliver public health, notably around leadership, management and interagency working, have featured more strongly in the curriculum, to complement the traditional scientific basis of public health practice, and to ensure a flexible workforce fit for purpose in today's complex array of contexts in which public health is practised.

The delivery of specialist training in public health and all medical and dental specialties is the responsibility of deaneries, regional organisations who commission, implement and monitor postgraduate training for doctors and dentists, with entry to training by open competition. This five year training programme includes one full year for completion of a Masters level course in a relevant subject. Although the Masters is not a mandatory part of training, it is seen as an efficient way of providing trainees with the knowledge base required for their professional examinations. Some applicants will have acquired a postgraduate degree prior to entering training. The current specialist training is a competency based educational programme, which uses both formal examination and workplace-based assessment. The examination for membership of the Faculty comprises a traditional written exam, primarily knowledge-based (Part A), ${ }^{19}$ and an innovative 'shows how' Observed Structured Public Health Examination (OSPHE, Part B) ${ }^{20}$ In addition to the requirement to pass professional examinations, trainees in public health, currently known as Specialty Registrars, complete a training portfolio. A formal annual assessment ensures satisfactory progress is being made towards acquisition of programme competencies. Remedial training is prescribed when deemed necessary and rarely the trainee will repeat a period of training. Should the trainee persistently fail to make satisfactory progress, s/he can be removed from the training programme. In the UK the professional training structures are similar to that in Ireland, Malta, Australia and Hong Kong, although the detailed competencies vary. The modern curriculum covers nine main areas of competence, as outlined in Table 2.

These nine key areas relate to the three domains of public health practice identified by the FPH (health protection, health improvement and service quality) and are derived from a description of what a public health consultant actually does. Whilst developed de novo for a UK-based specialty, it is of note that they are congruent to some significant degree with the Essential Public Health Functions identified by $\mathrm{WHO}^{21}$ and with CDC's ten Essential Public Health Services ${ }^{22}$ as far as they are applicable to competency 
development in the UK context. In addition to the nine key areas, it is recognised that public health specialists require the ethical management of oneself and "professionalism", which are defined through a set of key concepts and underlying values called 'Good Public Health Practice'. These mirror for public health specialists the General Medical Council's 'Good Medical Practice', ${ }^{23}$ which is applicable to all registered doctors, although, of course, they now apply to all public health specialists from all professional backgrounds.

Table 2

Nine Key Areas of Competence in the UK Faculty of Public Health Curriculum

\begin{tabular}{|c|c|}
\hline Key area 1 & Surveillance and assessment of the population's health and wellbeing. \\
\hline Key area 2 & $\begin{array}{l}\text { Assessing the evidence of effectiveness of interventions, programmes and } \\
\text { services intended to improve the health or wellbeing of individuals or } \\
\text { populations. }\end{array}$ \\
\hline Key area 3 & Policy and strategy development and implementation. \\
\hline Key area 4 & Strategic leadership and collaborative working for health. \\
\hline Key area 5 & Health improvement. \\
\hline Key area 6 & Health protection. \\
\hline Key area 7 & Health and social service quality. \\
\hline Key area 8 & Public health intelligence. \\
\hline Key area 9 & Academic public health. \\
\hline
\end{tabular}

Source: The UK's Faculty of Public Health. Available from URL: www.fph.org.uk (Accessed 24 January, 2011).

Other than time spent on the Masters course, public health trainees spend all of their time in 'real-life' training placements, including public health departments in the NHS and local government, academic departments of public health and epidemiology, and also in a smaller number of placements approved for training in other sectors and internationally, such as the Health Protection Agency, government departments and the World Health Organisation. In any given placement the trainee and educational supervisor agree on the competencies to be acquired during the placement. The trainee maintains a portfolio to ensure that, by the end of the five-year training programme, $\mathrm{s} / \mathrm{he}$ has acquired all of the required competencies. 


\section{THE DEVELOPMENT OF THE WIDER PUBLIC HEALTH WORKFORCE}

Apart from some changes in the administrative and organisational arrangements of training and its quality assurance, the professional specialist training system was quite stable until the late 1990's, when the drive towards the creation of a multidisciplinary specialist workforce led to the establishment of training programmes to accommodate trainees from backgrounds other than medicine. Change was patchy, with some regions setting up parallel training programmes for non-medical trainees and others integrating training fully, from recruitment into the programme to completion. In 2010, the integrated model is now the norm. In most parts of England and in Wales, but not the whole of the UK, the majority of public health specialists in training currently come from non-medical backgrounds, but it remains a popular career choice for doctors too, and training programmes are over-subscribed. Of those applicants from non-medical backgrounds, some come from clinical disciplines, including nursing, physiotherapy, speech therapy, and pharmacy, while others have backgrounds as diverse as geography, history, anthropology, social sciences, psychology, health informatics and epidemiology. All are required to complete the FPH curriculum in the five-year duration of training. Some training schemes offer induction programmes for those trainees who have no experience of a clinical or scientific environment. Whilst it might be expected, for example, that specialists from clinical backgrounds move into posts that require clinical competencies, there is not yet published evidence that trainees from different professional backgrounds do progress to different types of specialist employment; this is an area ripe for research.

In 2001, the Chief Medical Office for England published a report called "Strengthening the Public Health Function", ${ }^{24}$ which identified three categories within the workforce: specialist, practitioner and 'wider'. The report promoted recognition of the importance of the contribution made by people in a wide variety of occupations and sectors of employment who either possess or need public health skills, sometimes at specialist, but often at a more basic level, who are key to development of a true multidisciplinary public health workforce. ${ }^{25}$ In 2008, a national Public Health Skills and Careers Framework ${ }^{16}$ was developed for the English Department of Health, setting out the competencies required by these three non-hierarchical categories for effective practise. So, for example, it is possible to use the Framework to see the types of public health competencies recommended for a local government Chief Executive Officer, a family doctor or even a restaurateur! 
Whilst medically and dentally qualified public health specialists are required to be registered with their respective standard setting organisations (General Medical Council and the General Dental Council), until 2003 no regulatory framework existed for specialists from other backgrounds. The UK Voluntary Register for Public Health Specialists (known as the Public Health Register or UKPHR) was established in 2003 and meets an important need in terms of public confidence, as the regulator for public health specialists who would not otherwise be registered. UKPHR remains a voluntary register, and as such it has no legally enforceable powers. Statutory professional regulation for all public health professionals remains the subject of ongoing consideration and has been raised again in a recent English government White Paper on Public Health ${ }^{26}$ and the Review of Regulation of Public Health Professional ${ }^{27}$ published at the same time and which recommend statutory regulation for all. The intended introduction in the UK of revalidation for doctors from 2012 and subsequently for other health professionals will bring for the first time a legal requirement to remain up to date in order to retain a licence to practise which, in turn, will increase demand for expansion of continuing professional education in the field.

\section{LINKS BETWEEN ACADEMIC AND SERVICE PUBLIC HEALTH}

Innovation in the practice of public health is in many ways dependent on the research and development taking place within academic public health and its communication to both the current and the next generation of public health professionals. In the UK the strength of relationships between these two worlds has varied both with time and by region. One key factor that limits collaborative working is that, unlike the US and some European countries, the university sector does not oversee professional training in public health, which is the domain of the NHS. The role of the universities has generally been confined to the provision of the theoretical knowledge underpinning the practice of public health with less day-to-day involvement in arranging practical work-based placements.

Over the last 40 years there have been numerous initiatives designed to strengthen links which have had varying impact. The 1970's saw an expansion of academic departments of community medicine within medical schools, and public health teaching began to feature in undergraduate medical curricula. In the 1980's there were calls for the establishment of more schools of public health in Britain based on the LSHTM and US models. A small number did emerge but tended to be organised as networks of universities and other public health organisations working together to 
tackle key health issues in their local population rather than modelled on single institutions. However, the concept never really took hold. Today the term "School of Public Health" is synonymous with a collection of academics within a university from a wide range of disciplines related to public health involved in programmes of research and teaching. It is not a widely used term, with many such groupings of public health academics identifying themselves as departments or faculties within their universities. More recently, it has also been possible for doctors, both soon after leaving medical school and later, at the point of specialisation, to undertake placements in academic public health settings. The Academic Clinical Fellowship and Lectureship programme allows 25 percent of specialty training time to be spent in an academic department developing research skills. These programmes attract healthy numbers of applicants and it is hoped that despite there being less than 50 posts available annually across England the impact of this relatively new scheme will be cumulative. In addition, trainees in public health specialty training programmes outside of this scheme are also able to undertake academic placements of up to one year towards the end of their training.

Links at a senior level are more limited and largely centre on academic input into continuing professional development (CPD), such as seminar series, conferences or master classes. Some university departments receive NHS funding to offer consultancy-based input to local public health organisations. The university funding system may exacerbate the divide, driving staff to focus on the acquisition of research grants and scientific publications rather than the practical application of their work.

\section{THE FUTURE OF PUBLIC HEALTH EDUCATION AND TRAINING IN THE UK}

The education and training of future public health professionals in the UK is a constantly evolving process, influenced by both the determinants of health and the context in which public health is practiced. In the UK, there are changes in both of these spheres. The reorganisation of the $\mathrm{NHS}^{28}$ and public health system ${ }^{26}$ within it in England, proposed by the current government, will have major implications for the skills required for future public health professionals as they work in new environments. Public health education and training will also need to evolve to meet wider challenges. Health inequalities persist in the UK compounded by global threats such as climate change and the economic crisis, which are increasingly being experienced at a local level. 


\section{Current Challenges}

A number of the changes proposed for the NHS in England are likely to have a major impact on the public health system, and in turn on education and training. Firstly, there are plans to merge a number of quasi-independent public health organisations such as the Health Protection Agency (whose remit is to protect the public from infectious diseases and other noncommunicable hazards) into a single public health body, Public Health England, which will be part of the Department for Health. Secondly, following the abolition of NHS PCTs, which employ the majority of specialist public health professionals, public health teams will relocate to Local Authorities. It is also likely that an increasingly wider range of providers from the private and voluntary sectors will enter the healthcare market. The loss of independence for the public health workforce, should the transition into political organisations, such as the Department of Health and Local Authorities take place, will present difficulty in freely advocating for better public health against other interests. Finally, family doctors are earmarked to take over responsibility for the commissioning of health services from PCTs and uncertainty surrounds the level of input that public health specialists will have in the process. These changes are particularly challenging occurring as they do at a time of austerity with severe public sector spending cuts anticipated.

The FPH raised concerns about the potential risks of these proposals to the safe and effective delivery of public health in England including education and training and their impact on staff recruitment and retention. ${ }^{29}$ The fragmentation of the public health workforce into Local Authorities, Public Health England, commissioning bodies and other organisations may limit opportunities for skill-sharing and CPD by the profession and present difficulties in securing supervisors for trainees in new locations with smaller public health workforces. There are doubts as to which public health budgets will be controlled by public health professionals and fears that staff will face unfavourable pay and conditions at the new local authority locations as compared to the NHS. This may lead to loss of specialist staff during the transition, including FPH trainers, and pose recruitment difficulties. Furthermore, the increased fragmentation risks increasing professional isolation and makes it more challenging to move between locations as a qualified professional. This adds to concerns that the diverse career opportunities which make the practice of public health so attractive to many may be considerably diminished and thus affect recruitment of high calibre candidates. ${ }^{30}$ 
Financial constraints affecting other sectors may also result in changes to public health education. From 2012, university student tuition fees are set to rise as high as $£ 9000$ per year as government funding to higher education institutions is reduced. ${ }^{31}$ This has raised fears that students, particularly those from poorer backgrounds, may be discouraged from going to university, which in turn, may jeopardise the viability of some of the newer undergraduate and postgraduate courses featuring public health. Many of these courses are found in more recently established universities which tend to be more dependent on teaching income and are more vulnerable to student loss. ${ }^{32}$ The loss of diversity in the public health workforce may be a longer term consequence.

Whilst the exact nature of effects of the changes to the English health and education systems are as yet unknown, there is a stronger consensus on the future challenges to the population's health across the four nations, which will form the basis for future public health practice. Global issues will increasingly be at the fore of public health, for example: the economic crisis; climate change; the role of multinational companies in health behaviours, such as tobacco, alcohol and food consumption; the emergence of new infectious diseases; and biological terrorism. These issues are exacerbating already challenging problems, most notably, the widening health inequalities in society.

\section{Future Solutions}

With changes come fresh opportunities, and the profession has already demonstrated its ability to adapt and benefit from past changes. The long established tradition of public health education and more recent adoption of competency-based approaches to training give some flexibility to meet these challenges. However, insight and innovative responses are required to ensure that public health education and training are not destabilised by these challenges. A number of potential options for the future direction of the public health system have been proposed by the FPH, academics and the British Medical Association. ${ }^{29,33,34}$ A unifying theme is a call for a central public health body, ideally located within the NHS and outside of the Department of Health. This approach would overcome issues relating to fragmentation, recruitment and training and the ability to be act as an independent, authoritative voice on public health.

The availability of a wider range of training placements in the future offers opportunities to improve, expand and strengthen public health speciality training. Placements in general practitioner consortia could provide the opportunity to gain expertise in health service commissioning 
and management, those in Local Authorities, experience in tackling the wider determinants of health in collaboration with social care and environmental health professionals, and placements in Public Health England training in research, evaluation and policy development.

To ensure that these opportunities are offered to trainees, a clear focus and leadership from postgraduate deaneries and the FPH will be essential. A first step would be to begin to scope out potential training locations, determine the knowledge and skills needed to work in these, adapt the curriculum both within academic courses and the competency framework and ensure that diverse placements are available to meet the full range of competencies demanded of public health professionals. Some new locations such as Local Authorities do not have a tradition of public health training, and gaining organisational commitment will be necessary. Trainees in new locations will potentially be exposed to a wider range of trainers who in turn will need educational development.

The new knowledge and skills requirements of public health professionals will include a greater fluency in economic parlance and methods, such as cost-effectiveness analyses and strong political skills including leadership and advocacy. The ability to work collaboratively in broad networks spanning local, regional and national bodies and across academic, private and public sectors will facilitate implementation of appropriate interventions to tackle issues related to globalisation and climate change. A key step to achieving this is to train public health professionals to effectively bridge the gap between evidence and policy.

\section{CONCLUSION}

The last century has seen tremendous change in public health practice as its focus of attention has shifted from the control of infectious disease, through health inequalities and the consequences of demographic shifts and onto mitigating the impact of global phenomena. Although the UK has a long history of training and education in the field of public health, those involved in its provision have had to adapt in order to provide curricula and training opportunities that best prepare their students for the future challenges they might face in the constantly changing workplace. In the UK there are, however, a number of elements in place that mitigate against these pressures. Key amongst these is the competency-based professional training pathway. By its nature it individualises the learning process and can be adapted to match the challenges faced by the profession as a whole. ${ }^{35}$ It also provides 
objective evidence of training progression and has been used in the UK to determine roles across a diverse public health workforce.

Developed later than some countries perhaps, but now established, the public health profession in the UK and particularly in England is truly multidisciplinary and offers the same training opportunities to a range of individuals from a variety of backgrounds.

Further development in training and education will be required in order to meet the challenges ahead. Public health will be practised in a wider range of settings in the future and trainees need exposure to these settings to be prepared for that future. This may be difficult in organisations where training has not been traditional. Postgraduate university courses and competency-based curricula need to adapt to ensure that graduates leave with the knowledge and skills to practice effectively in a range of environments where skills such as leadership, communication of complex ideas and advocacy will determine whether those organisations take on board their responsibilities to promote and protect the public health. Closer collaborative working across academic and service public health will bolster this effort. History suggests that, despite the challenges, the UK will continue to have robust public health education and training to prepare the next generation of public health professionals.

\section{Acronyms List:}

$\mathrm{CPD}=$ Continuing professional development

$\mathrm{FPH}=$ Faculty of Public Health

GMC $=$ General Medical Council

LSHTM $=$ London School of Hygiene and Tropical Medicine

MOsH $=$ Medical Officer of Health

NHS $=$ National Health Service

PCT $=$ Primary Care Trust

UKPHR = UK Public Health Register

\section{Terms and definitions list:}

Masters - A degree awarded usually after one year of advanced graduate study beyond a bachelors' degree.

Faculty of Public Health - The standard setting body for specialists in public health in the United Kingdom.

Professional specialist training in public health - A competitive entry programme of five years duration which leads to accreditation as a Consultant in Public Health and usually consists of a one year Masters course and four years of practical placements.

Primary Care Trust - A National Health Service organisation which funds primary care provision, provides or commissions community services and commissions secondary care for local populations of 100,000 to 200,000 people. This is the setting where most UK public health specialists currently work. 


\section{Key Points:}

- Academic teaching in public health in the UK has been established for many years and is provided at an increasing number of universities.

- Public health became a recognised medical specialty in the 1970 s and at the same time professional specialist training in public health within the NHS was established.

- Public health is the first medical specialty whose training is open to medical and non-medical applicants.

- Academic departments of public health support education and training in public health by providing Bachelor and Masters degrees and supporting the work of public health professionals in NHS settings. The level of this support varies from region to region.

- The quality of public health education and training faces challenges in the coming years including the proposed NHS reorganisation and financial constraints faced by universities.

- The curriculum of university courses and professional specialist training will need to adapt in order to better prepare future public health practitioners for work in a wide variety of settings.

\section{Future Issues List:}

- The NHS is facing one of the biggest structural changes since its formation with potential fragmentation of the public health workforce across many organisations. Protecting the quality of professional training across these sites will be important.

- The UK is at a point when the structure of professional training in public health is under revision. This may result in a bigger involvement of universities and their medical schools in the organisation of that training. The School of Public Health model may once more be considered as an organisational model along with alignment with European public health competencies and formal accreditation of academic postgraduate public health courses.

Conflicts of Interest: None declared.

\section{REFERENCES}

1. Chadwick E. Report on the sanitary condition of the labouring population of great britain. A supplementary report on the results of a special inquiry into the practice of internment in towns. London: Her Majesty's Stationery Office; 1843.

2. Black D. Inequalities in Health. Public Health. 1991;105:23-7.

3. Sims M, Maxwell R, Bauld L, Gilmore A. Short term impact of smoke-free legislation in England: retrospective analysis of hospital admissions for myocardial infarction. BMJ. 2010;340:c2161.

4. Warren MD. The origins of the Faculty of Public Health Medicine (formerly Faculty of Community Medicine). London: Faculty of Public Health; 2000.

5. Fee A, Acheson R, (editors). A history of education in public health. Oxford: Oxford University Press; 1991. 
6. Frazer WM. A history of English public health, 1834-1939. London: Bailliere, Tindall and Cox; 1950.

7. Flexner A. Medical education in the United States and Canada: a report to the Carnegie Foundation for the Advancement of Teaching. New York: The Carnegie Foundation for the Advancement of Teaching; 1910.

8. Welsh WH, Rose W. Institute of Hygiene: a report to the General Education Board of Rockefeller Foundation. New York: The Rockefeller Foundation; 1915.

9. Wilkinson L, Hardy A. Prevention and cure. The London School of Hygiene and Tropical Medicine. A 20th century quest for global public health. London: Kegan Paul Limited; 2001.

10. Acheson D. Public health in England. Report of the committee of inquiry into the future development of the public health function. London: HMSO; 1988.

11. Public Health Online Resource for Careers, Skills and Training (PHORCaST). Available from URL: www.phorcast.org.uk (Accessed 22 January, 2011).

12. Find a Masters. Available from URL: http://www.findamasters.com/search/ courses.aspx?keywords=public+health (Accessed 24 January, 2011).

13. The Quality Assurance Agency for Higher Education, Master's degree characteristics. QAA; 2010.

14. UCAS. Available from URL: http://www.ucas.ac.uk/ (Accessed 24 January, 2011).

15. Faculty of Public Health. FPH Training Curriculum. Available from URL: www.fph.org.uk (Accessed 24 January, 2011).

16. Skills for Health UK. Public health skills and career framework. Public Health Resource Unit; 2008. Available from URL: http://www.skillsforhealth.org.uk (Accessed 23 January, 2011).

17. Bologna Process. Available from URL: http://www.ond.vlaanderen.be/ hogeronderwijs/bologna/ (Accessed 13 April, 2011).

18. Faculty of Public Health. Faculty of Public Health Training Currciculum 2010. Available from URL: www.fph.org.uk (Accessed 23 January, 2011).

19. Faculty of Public Health. Faculty of Public Health Part A Examination. Available from URL: http://www.fph.org.uk/part_a_exam (Accessed 23 January, 2011).

20. Faculty of Public Health. Faculty of Public Health Part B Examination. Available from URL: http://www.fph.org.uk/part_b_exam_osphe (Accessed 23 January, 2011).

21. Yach D. Redefining the scope of public health beyond the year 2000. Curr Issues Public Health. 1996;2:247-52.

22. National Public Health Preformance Standards Program. 10 essential public health services. NPHPSP, Centers for Disease Control and Prevention. Available from URL: http://www.cdc.gov/nphpsp/essentialServices.html (Accessed 8 July, 2011).

23. General Medical Council. Good medical practice. Guidance for doctors. London: GMC; 2006. Available from URL: http://www.gmc-uk.org/static/ documents/content/GMP_0910.pdf (Accessed 11 July, 2011). 
24. Chief Medical Officer, Department of Health. The report of the Chief Medical Officer's Project to Strengthen the Public Health Function. London: DOH; 2001. Available from URL: http://www.dh.gov.uk/prod_consum_dh/groups/ dh_digitalassets/@dh/@en/documents/digitalasset/dh_4062359.pdf (Accessed 11 July, 2011).

25. Sim F, Lock K, McKee M. Maximising the contribution of the public health workforce: the English experience. Bull World Health Organ. 2007; 85:935-40.

26. Department of Health. Healthy lives, healthy people White paper: our strategy for public health in England. London: DOH; 2010. Available from URL: http://www.dh.gov.uk/en/Publichealth/Healthyliveshealthypeople/index.htm (Accessed 11 July, 2011).

27. Department of Health. Review of the regulation of public health professionals. London: DOH; 2010.

28. Department of Health. Equity and Excellence: Liberating the NHS. London: DOH; 2010.

29. Faculty of Public Health. UK Faculty of Public Health response to healthy lives, healthy people: our strategy for public health in England. London: FPH; 2011 Available from URL: http://www.fph.org.uk/uploads/FPH\%20 response $\% 20$ to $\% 20$ Healthy $\% 20$ Lives, $\% 20$ Healthy $\% 20$ People $\% 20-\% 20$ Our\%20strategy $\% 20$ for $\% 20$ public $\% 20$ health $\% 20$ in $\% 20$ England $\% 20-\% 20$ FINAL.pdf (Accessed 4 April, 2011).

30. Anderson B. Trained on the future? Public Health Today. February 2011, p. 11.

31. Browne J. Securing a sustainable future for higher education. An independent review of higher education funding and student finance. 2010. Available from URL: www.independent.gov.uk/browne-report (accessed 4 April, 2011).

32. University and College Union. UCU Summary and Observation of Browne Report. UCU; 2010.

33. British Medical Association. Response to healthy lives, healthy people. BMA; 2011. Available from URL: http://www.bma.org.uk/images/ healthyliveshealthypeoplemainresponse_tcm41-205192.doc (Accessed 4 April, 2011).

34. McKee M, Hurst L, Aldridge RW, Raine R, Mindell JS, Wolfe I, Holland WW. Public health in England: an option for the way forward? Lancet. Feb 2011. [Epub ahead of print] DOI: 10.1016/S0140-6736(11)60241-9.

35. Gruppen LD, Mangrulkar RS, Kolars JC. Competency-based education in the health professions: implications for improving global health. Commission paper. 2010. Available from URL: http://www.healthprofessionals21.org/ docs/CompBasedEd.pdf (Accessed 11 July, 2011). 